\title{
Morphological and physiological studies on Indian national kabaddi players
}

\author{
S. K. Dey, G. L. Khanna* and M. Batrat \\ Human Performance Laboratory, Sports Authority of India, N.S. Eastern Centre, *Sports Authority of India, \\ N.S. Southern Centre, Bangalore, tSports Authority of India, J.N. Stadium, New Delhi, India
}

Twenty-five national kabaddi players (Asiad gold medallists 1990), mean age 27.91 years, who attended a national camp at the Sports Authority of India, Bangalore before the Beijing Asian Games in 1990, were investigated for their physical characteristics, body fat, lean body mass (LBM) and somatotype. The physiological characteristics assessed included back strength, maximum oxygen uptake capacity and anaerobic capacity (oxygen debt) and related cardiorespiratory parameters (oxygen pulse, breathing equivalent, maximum pulmonary ventilation, maximum heart rate). Body fat was calculated from skinfold thicknesses taken at four different sites, using Harpenden skinfold calipers. An exercise test (graded protocol) was performed on a bicycle ergometer (ER-900) using a computerized EOS Sprint (Jaeger, West Germany). The mean(s.d.) percentage body fat (17.56(3.48)) of kabaddi players was found to be higher than normal sedentary people. Their physique was found to be endomorphic mesomorph (3.8-5.2-1.7). Mean(s.d.) back strength, maximum oxygen uptake capacity $\left(\dot{V}_{\mathrm{O}_{2}} \max \right)$ and oxygen debt were found to be $162.6(18.08) \mathrm{kg}, 42.6(4.91) \mathrm{ml} \mathrm{kg}^{-1} \mathrm{~min}^{-1}$ and 5.02(1.29) litre respectively. Physical characteristics, percentage body fat, somatotype, maximum oxygen uptake capacity and anaerobic capacity (oxygen debt) and other cardiorespiratory parameters were compared with other national counterparts. Present data are comparable with data for judo, wrestling and weightlifting. Since no such study has been conducted on international counterparts, these data could not be compared. These data may act as a guideline in the selection of future kabaddi players and to attain the physiological status comparable to the present gold medallists.

Keywords: Kabaddi, body fat and somatotype, $\dot{V}_{\mathrm{O}_{2} \max }$

Kabaddi is a traditional outdoor game played with minor variations in all regions of India - in fact, in most parts of Asia. It is an ancient backyard and homegrown game.

Kabaddi requires tremendous physical stamina, agility, individual proficiency, neuromuscular coordination, lung capacity, quick reflexes, intelligence and presence of mind on the part of both attackers and defenders.

Address for correspondence: Dr S. K. Dey, Human Performance Laboratory, Sports Authority of India, N.S. Eastern Centre, Salt Lake City, Calcutta 700091, India

(C) 1993 Butterworth-Heinemann Ltd 0306-3674/93/040237-06
It needs a small playing area, 14 players (seven on each side) take part and no equipment is required. The dimensions of the playing field are $12.5 \times 10 \mathrm{~m}$ (for adults) divided by a mid-line into two equal halves (each $6.25 \times 10 \mathrm{~m}$ ) (Figure 1). Each half is the territory of a team (one for the raiders and the other for the defenders). The game is supervised by a referee, two umpires and a scorer. The side winning the toss has the option of sending their raiders first, or choosing a particular side. The raider takes the maximum possible inspiration and then moves to the other side of the field, uttering a continuous chant 'Kabaddi' without any further inspiration, to try to touch one of the defending players. The defenders try to hold the raider within their area and the raider tries to force his way back to his own side without discontinuing the chant. If the raider is able to come back to his area after touching a defender a point is credited to his group and the person touched is put out of the game. On the other hand, the defending group gets a point if they can hold the raider, who

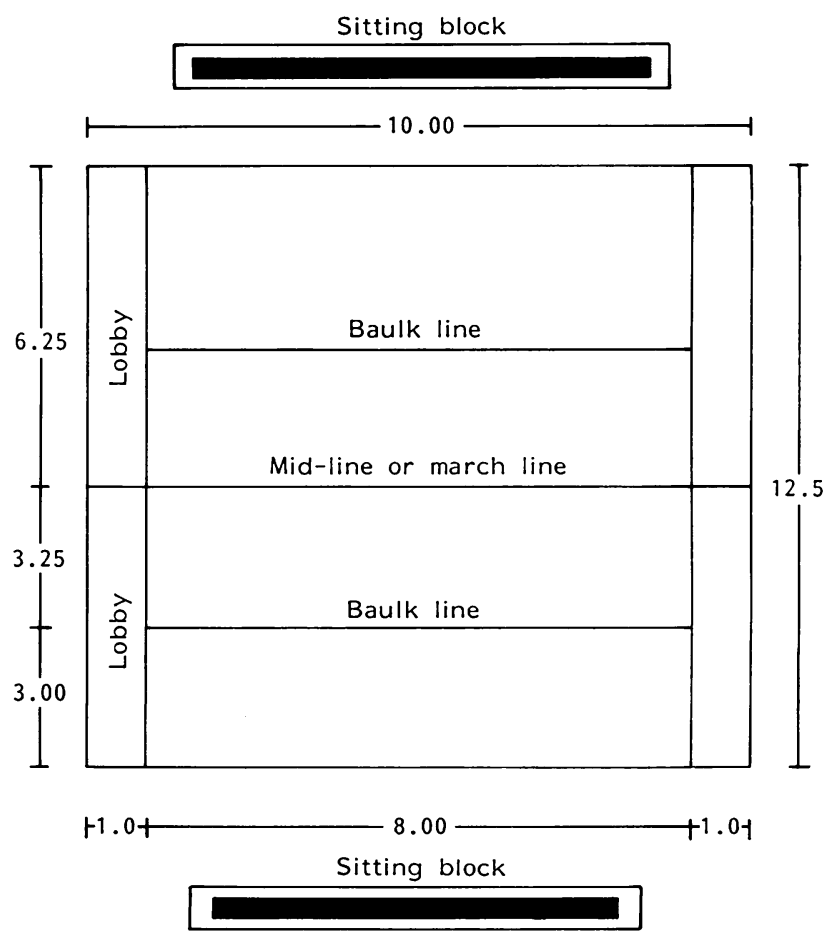

Figure 1. Kabaddi court for men, measurements in metres 
then has to drop out. If a player is put out from one side, a player who had earlier been eliminated from the opposite group then rejoins his own side. A person from each group alternately raids the opposite side. This process continues until a team succeeds in putting out the entire opposing team. The successful side is then credited with two additional points (Lona). Also if any player goes out of the boundary line during the course of play, or if any part of his body touches the ground outside the boundary, he will be out (except during a struggle). The side scoring maximum points at the end of play is declared the winner. The time of play is $40 \mathrm{~min}$ with an interval of $5 \mathrm{~min}$.

Since kabaddi is an intermittent type of sport, it requires both aerobic, anaerobic endurance with a well built physique. No physiological study on kabaddi players is available on national or international players except for some pulmonary function tests that have been done on Indian inter-university players ${ }^{1}$. The present investigation of Indian national kabaddi players was undertaken (1) to study morphological and physiological parameters; (2) to study adaptive changes in these players compared with other sports disciplines; (3) to use these data to determine the 'norms' for comparison.

\section{Subjects and methods}

The present study was carried out on 25 national kabaddi players who won the gold medal in the 1990 Asiad at Beijing. They were attending a camp at the Sports Authority of India, Bangalore before the Asian games and the study was conducted 2 weeks before the performance trial. The physical characteristics of the subjects including age (years), height $(\mathrm{cm})$, weight $(\mathrm{kg})$, body fat $(\%)$ and lean body mass (LBM) were measured.

\section{Body fat and somatotype}

Skinfold thicknesses were measured by Harpenden skinfold calipers at the sites of biceps, triceps, subscapular, suprailiac and calf. Somatotype $(\mathrm{H}-\mathrm{C})$ was calculated using the equation of Heath and Carter $^{2}$ and body fat percentage and lean body mass were calculated by the formula of $\operatorname{Siri}^{3}$. Body density was calculated using the equations of Durnin and Rahaman ${ }^{4}$. Back strength was measured with the help of a back dynamometer.

\section{Maximum aerobic capacity}

The maximum aerobic capacity was assessed during a continuous incremental workload on a Jaeger bicycle ergometer (ER-900). The exercise protocol of Sport-1 designed by Jaeger and Company (Würzburg, Germany) in EOS-Sprint was applied. This protocol consists of three phases.

\section{Reference phase}

During this phase $2 \mathrm{~min}$ of exercise was given without any workload at 60 r.p.m.

\section{Test phase}

In this phase, the workload was increased by 50 watt every $2 \mathrm{~min}$ until complete exhaustion. The oxygen consumption $\left(\dot{V}_{\mathrm{O}_{2}}\right)$ at the maximum effort and showing no further rise with the increase of workload was taken as maximum aerobic capacity $\left(\dot{V}_{\mathrm{O}_{2} \text { max }}\right)$. The physiological parameters, heart rate (HR), breathing frequency (BF), respiratory quotient (RQ), fraction of carbon dioxide $\left(\mathrm{FCO}_{2}\right)$, fraction of oxygen $\left(\mathrm{FO}_{2}\right)$, pulmonary ventilation $(\dot{V} \mathrm{E})$ were monitored by the computerized EOS-Sprint System every $30 \mathrm{~s}$. The subjects were verbally encouraged throughout the test to continue cycling until maximum exhaustion. The details of the procedures were explained to the subject before the onset of the exercise test.

\section{Recovery phase}

In the recovery phase the physiological parameters were monitored until the oxygen consumption returned to the normal resting level. Oxygen debt was calculated by the standard method described by Fox et al. ${ }^{5}$.

The whole experiment was performed at a room temperature varying from $23^{\circ}$ to $25^{\circ} \mathrm{C}$ with the relative humidity varying between 50 and $60 \%$.

\section{Statistical analysis}

Mean, standard deviation, standard 'norms' simple and multiple correlation coefficients and regression equations of various morphological and physiological parameters were computed.

\section{Results}

Means and standard deviations of physical characteristics, somatotype and cardiorespiratory variables are presented in Table 1. Table 2 represents the median value with the range of values measured in different

Table 1. Physical characteristics, somatotype and cardiorespiratory variables of Indian national kabaddi players

\begin{tabular}{|c|c|}
\hline Variable & Mean(s.d.) \\
\hline Age (years) & 27.91(3.42) \\
\hline Weight (kg) & $75.49(5.13)$ \\
\hline Height $(\mathrm{cm})$ & 174.34(4.33) \\
\hline Fat $(\%)$ & $17.56(3.48)$ \\
\hline Lean body mass $(\mathrm{kg})$ & $62.18(4.25)$ \\
\hline Endomorphy & $3.83(1.06)$ \\
\hline Mesomorphy & $5.18(1.12)$ \\
\hline Ectomorphy & $1.69(0.69)$ \\
\hline$\hat{V}_{\mathrm{O}_{2} \max }\left(\mathrm{Imin}^{-1}\right)$ & $3.21(0.39)$ \\
\hline$\dot{V}_{\mathrm{O}_{2 \max }}\left(\mathrm{ml} \mathrm{kg}^{-1} \mathrm{~min}^{-1}\right)$ & $42.61(4.91)$ \\
\hline$\dot{V} E_{\max }\left(I \min ^{-1}\right)$ & 132.35(18.15) \\
\hline Oxygen debt $\left(\mathrm{min}^{-1}\right)$ & $5.02(1.29)$ \\
\hline Oxygen pulse ( $\mathrm{ml}$ per beat) & $17.42(2.17)$ \\
\hline Breathing equivalent & $41.50(5.69)$ \\
\hline Back strength $(\mathrm{kg})$ & $162.56(18.08)$ \\
\hline$H R_{\max }\left(\right.$ beat $\left.\min ^{-1}\right)$ & 184.52(7.01) \\
\hline Recovery heart rate* (beat $\min ^{-1}$ ) & $165.76(8.74)$ \\
\hline
\end{tabular}

$H R_{\text {max }}$, maximum heart rate

${ }^{*}$ After 1 min of maximum exercise 
physical and physiological parameters. Table 3 comprises the matrix of correlation coefficients for various physical and physiological variables. Significant positive correlation $(P<0.05)$ was observed when maximum oxygen uptake capacity was correlated with weight and LBM ( $r=0.43$ and $r=0.39)$. Total percentage body fat was also positively correlated with endomorphic and mesomorphic components $(r=0.99$ and 0.41$)$ and negatively correlated with ectomorphic components $(r=-0.62)$. The above correlations were significant at the probability levels

Table 2. Morphological and physiological parameters of kabaddi players

\begin{tabular}{|c|c|}
\hline Parameter & Median (min-max) \\
\hline 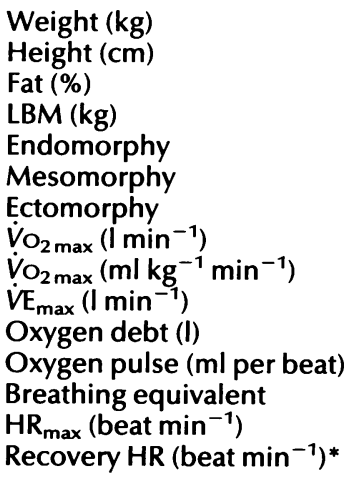 & $\begin{array}{c}75.30(70.02-84.26) \\
173.81(168.60-177.30) \\
16.96(12.98-20.34) \\
61.75(57.20-66.05) \\
3.61(2.89-5.01) \\
5.07(4.31-5.89) \\
1.48(1.12-2.08) \\
3.12(3.01-4.21) \\
42.10(38.56-49.70) \\
131.05(98.76-151.00) \\
4.98(4.29-6.06) \\
17.00(14.50-19.71) \\
41.12(33.48-44.12) \\
183.83(175.50-183.00) \\
165.04(117.20-149.00)\end{array}$ \\
\hline
\end{tabular}

*After 1 min of maximum exercise; LBM, lean body mass; HR, heart rate of $P<0.01$ and $P<0.05$, respectively. Weight was negatively correlated with ectomorphy $(r=-0.49)$. Maximum oxygen uptake capacity has no significant correlation with endomorphy, mesomorphy and ectomorphy. Significant positive correlation was also observed in back strength when correlated with age, height and weight $(r=0.46, r=0.60$ and $r=0.66$, respectively).

Table 4 comprises the multiple correlation coefficients and regression equations for body fat percentage, lean body mass and somatotype. These components were predicted from height and weight. The standard errors of the estimates for different parameters are within acceptable limits. Comparison of height, weight, body fat percentage, somatotype and $\dot{V}_{2}$ max of national kabaddi players with other Indian national counterparts (team) are presented in Table 5. Body somatotype (Figure 2) and aerobic capacity (Figure 3) of different Indian national teams were compared with the present study.

\section{Discussion}

Kabaddi is a game which combines the actions of wrestling, judo, rugby and gymnastics. The important body movements in this game involve catching, holding, locking and jumping, thus the possession of desirable anthropometric and physiological characteristics will have a greater advantage in executing a better performance in competition.

The mean height and weight of the subjects were found to be higher than those of the average Indian population ${ }^{6}$. The average body weight of the kabaddi

Table 3. Matrix of correlation coefficients for anthropometric and physiological parameters of national kabaddi players

\begin{tabular}{|c|c|c|c|c|c|c|c|c|c|}
\hline Age & Height & Weight & Fat & $L B M$ & Endomorphy & Mesomorphy & Ectomorphy & $\dot{V}_{\mathrm{O}_{2 \max }}$ & Strength \\
\hline $\begin{array}{l}\text { Age } \\
\text { Height } \\
\text { Weight } \\
\text { Fat } \\
\text { LBM } \\
\text { Endomorphy } \\
\text { Mesomorphy } \\
\text { Ectomorphy } \\
\dot{V}_{2 \text { max }} \\
\text { Strength }\end{array}$ & $0.42^{*}$ & $\begin{array}{l}0.35 \text { n.s. } \\
0.48^{*}\end{array}$ & $\begin{array}{r}-0.14 \text { n.s. } \\
0.32 \text { n.s. } \\
-0.28 \text { n.s. }\end{array}$ & $\begin{array}{c}0.50 t \\
0.83 t \\
0.65 t \\
-0.27 \text { n.s. }\end{array}$ & $\begin{array}{c}-0.18 \text { n.s. } \\
0.23 \text { n.s. } \\
-0.39^{*} \\
0.99 \dagger \\
-0.35 \text { n.s. }\end{array}$ & $\begin{array}{l}0.05 \text { n.s. } \\
0.40^{*} \\
-0.40^{*} \\
0.41^{*} \\
0.16 \text { n.s. } \\
0.46^{*}\end{array}$ & $\begin{array}{l}-0.05 \text { n.s. } \\
-0.49^{*} \\
0.52+ \\
-0.62 t \\
-0.14 \text { n.s. } \\
-0.63 t \\
-0.73+\end{array}$ & $\begin{array}{l}0.15 \text { n.s. } \\
0.38 \text { n.s. } \\
0.43^{*} \\
0.00 \text { n.s. } \\
0.39^{*} \\
-0.05 \text { n.s. } \\
-0.19 \text { n.s. } \\
0.03 \text { n.s. }\end{array}$ & $\begin{array}{c}0.46^{*} \\
0.60 \dagger \\
0.66+ \\
-0.20 \text { n.s. } \\
0.72 \dagger \\
-0.29 \text { n.s. } \\
-0.16 \text { n.s. } \\
0.07 \text { n.s. } \\
0.26 \text { n.s. }\end{array}$ \\
\hline
\end{tabular}

n.s., Not significant; $* P<0.05 ;+P<0.01 ;$ LBM, lean body mass

Table 4. Multiple correlation and regression equations for body fat, lean body mass and somatotype of national kabaddi players

\begin{tabular}{lcccc}
\hline Norms & Regression equations & $\begin{array}{c}\text { Multiple correlation } \\
\text { coefficient } \\
(R)\end{array}$ & $\begin{array}{c}\text { Coefficient of } \\
\text { determination } \\
\left(R^{2}\right)\end{array}$ & $\begin{array}{c}\text { Standard error } \\
\text { of estimate } \\
(s . e . e .)\end{array}$ \\
\hline Endomorphy & $-32.5+0.164 \mathrm{H}+0.102 \mathrm{~W}$ & 0.36 & 0.129 & 0.988 \\
Mesomorphy & $-40.78+0.197 \mathrm{H}+0.154 \mathrm{~W}$ & 0.81 & 0.648 & 0.978 \\
Ectomorphy & $-16.00+0.160 \mathrm{H}-0.136 \mathrm{~W}$ & 0.99 & 0.450 & 0.102 \\
Fat (\%) & $-93.13+0.490 \mathrm{H}+0.334 \mathrm{~W}$ & 0.67 & 0.483 & 3.580 \\
LBM & $23.71-0.101 \mathrm{H}+0.743 \mathrm{~W}$ & 0.69 & 3.055 \\
\hline
\end{tabular}

$H$, height; W, weight; LBM, lean body mass 
Studies on Indian national kabaddi players: S. K. Dey et al.

Table 5. Comparison of height, weight, percentage fat and somatotype of kabaddi players with other Indian national counterparts

\begin{tabular}{|c|c|c|c|c|c|c|}
\hline \multirow[t]{2}{*}{ Events } & \multicolumn{6}{|c|}{ Parameters } \\
\hline & Weight (kg) & Height $(\mathrm{cm})$ & Fat (\%) & Endomorphy & Mesomorphy & Ectomorphy \\
\hline Judo & $76.46(14.20)$ & $174.00(8.27)$ & $15.39(5.29)$ & $3.24(1.56)$ & $5.25(1.10)$ & $1.66(0.92)$ \\
\hline Boxing & $64.62(12.80)$ & $171.03(4.33)$ & $13.90(3.49)$ & $2.77(1.01)$ & $3.94(1.00)$ & $2.93(0.96)$ \\
\hline Cycling & $63.10(7.60)$ & $172.60(6.80)$ & $12.40(2.70)$ & $2.40(0.78)$ & $3.77(0.68)$ & $3.17(0.88)$ \\
\hline Weightlifting & $66.30(13.00)$ & $166.70(7.20)$ & $14.90(4.60)$ & $3.02(1.34)$ & $4.95(0.98)$ & $1.89(0.94)$ \\
\hline \multicolumn{7}{|l|}{ Wrestling } \\
\hline Light class & $55.80(4.70)$ & $159.50(6.80)$ & $12.20(2.10)$ & $2.40(0.62)$ & $4.83(0.81)$ & $2.04(0.75)$ \\
\hline Medium class & $72.80(7.20)$ & $170.70(6.70)$ & $15.80(3.10)$ & $3.62(1.09)$ & $5.34(0.89)$ & $1.47(0.76)$ \\
\hline Heavy class & $93.80(9.20)$ & $179.90(6.20)$ & $20.80(4.60)$ & $5.23(1.68)$ & $6.18(0.72)$ & $1.00(0.59)$ \\
\hline Football & $56.80(4.12)$ & $170.40(4.40)$ & $12.62(3.00)$ & $2.51(0.35)$ & $3.59(0.64)$ & $3.50(0.72)$ \\
\hline Hockey & $63.70(7.60)$ & $171.10(5.40)$ & $14.80(2.90)$ & $3.24(0.32)$ & $3.80(0.42)$ & $2.80(0.84)$ \\
\hline Volleyball & $67.90(5.80)$ & $181.20(5.10)$ & $13.20(2.80)$ & $2.60(0.41)$ & $3.30(0.06)$ & $3.90(0.77)$ \\
\hline Basketball & $62.50(7.30)$ & $178.70(6.50)$ & $13.30(3.80)$ & $2.53(0.97)$ & $3.37(0.66)$ & $4.03(1.01)$ \\
\hline Kabaddi & $75.49(5.13)$ & $174.34(4.33)$ & $17.56(3.48)$ & $3.83(1.06)$ & $5.18(1.12)$ & $1.69(0.69)$ \\
\hline
\end{tabular}

Values are mean(s.d.)

players was almost similar to judo players but heavier than footballers, hockey players and boxers, as reported by Sodhi and Sidhu' ${ }^{6}$. The total body fat percentage of the present kabaddi players was higher than the judokas, boxers, weightlifters, wrestlers (except the heavyweight category) and footballers ${ }^{6}$.

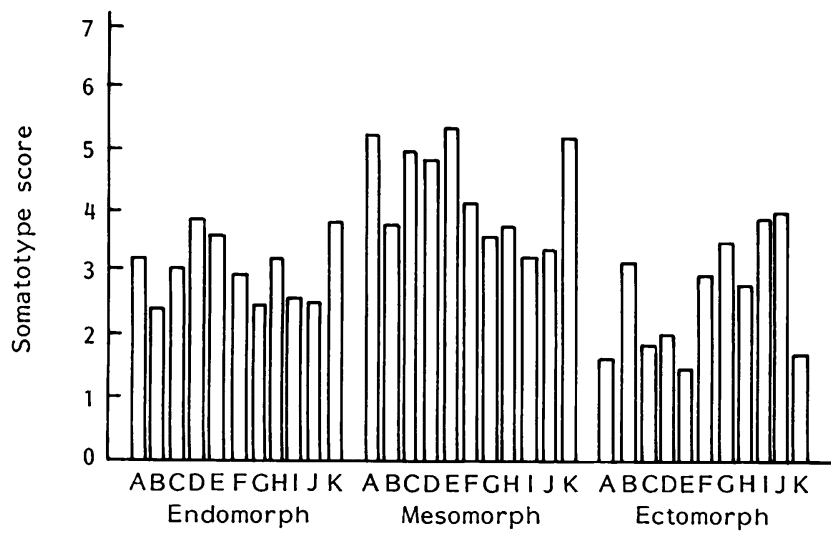

Figure 2. Somatotypes of Kabaddi players and national counterparts in other sports. A, judo; B, cycling (road); C, weightlifting; $D$, wrestling; $E$, cycling (track); $F$, boxing; $\mathrm{G}$, football; H, hockey; I, volleyball; J, basketball; K, kabaddi

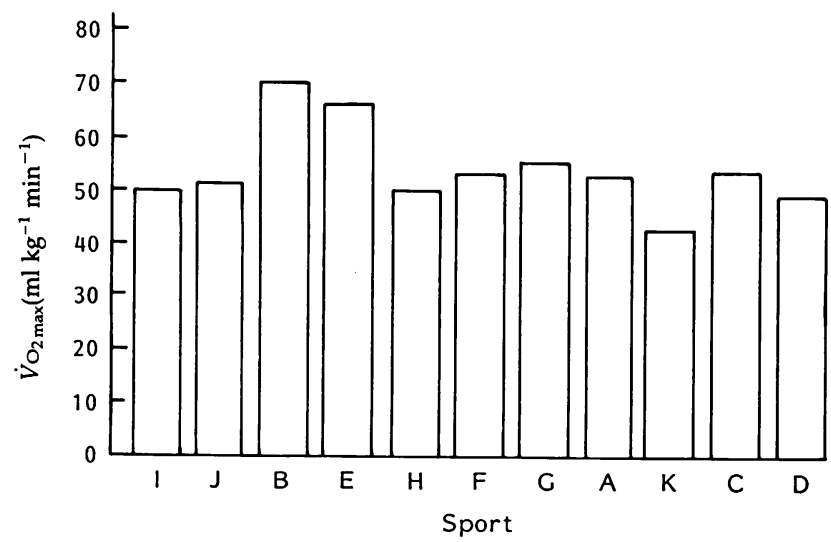

Figure 3. A comparison of the aerobic capacities of kabaddi players and national counterparts in other sports
Wrestling and weightlifting require a heavy body weight as suggested by Morehouse and Rasch ${ }^{7}$. The higher fat percentage in these kabaddi players may be due to their greater age (mean(s.d.) age was 27.91(3.42)). The somatotype of kabaddi players was found to be endomorphic mesomorph (3.83-5.181.69). The values are comparable to wrestlers (medium class), judo and weightlifters as reported by Sodhi and Sidhu ${ }^{6}$, only the endomorphic mesomorph rating is higher in the heavyweight category wrestlers.

The physique of the other performers reported by them was mainly mesomorphic-ectomorph, or balanced mesomorphy. The somatotype of weightlifters has been reported by different investigators as $3.0-6.5-1.0^{8}, 3.0-6.3-1.0^{9}$ and $2.4-7.1-1.0^{10}$. The present kabaddi players were found to be lower in the mesomorphic and higher in the endomorphic rating compared with the above mentioned sports. The somatotypes of British polytechnic rugby champions and French rugby players were reported by Reilly and Hardiker ${ }^{11}$ to be $4.0-5.2-5.0$ and by Boennec et al. ${ }^{12}, 3.0-5.0-3.0$, respectively. All the players had a predominant mesomorphic component, with the forwards having more endomorphic and less ectomorphic components than the backs. The physique of the present kabaddi players is comparable to the forward rugby players. In contact games, frailty or linearity in physique is commonly assumed to foster occurrence of injury, skeletal muscle is considered to protect underlying structures against external sources by presenting an intervening fleshy shield on impact ${ }^{13}$. The above observations are likely to reflect similar training techniques leading to a resemblance in somatotype in the present study.

Kabaddi requires many essential components such as strength, power, aerobic-anaerobic capacity, neuromuscular coordination and muscular endurance. Strength is one of the most important components of this game. In the present study the mean(s.d.) back strength of the kabaddi players $(162.56(18.08) \mathrm{kg})$ was found to be higher than for players of other games such as judo, boxing (except the heavyweight category) and wrestling. But 


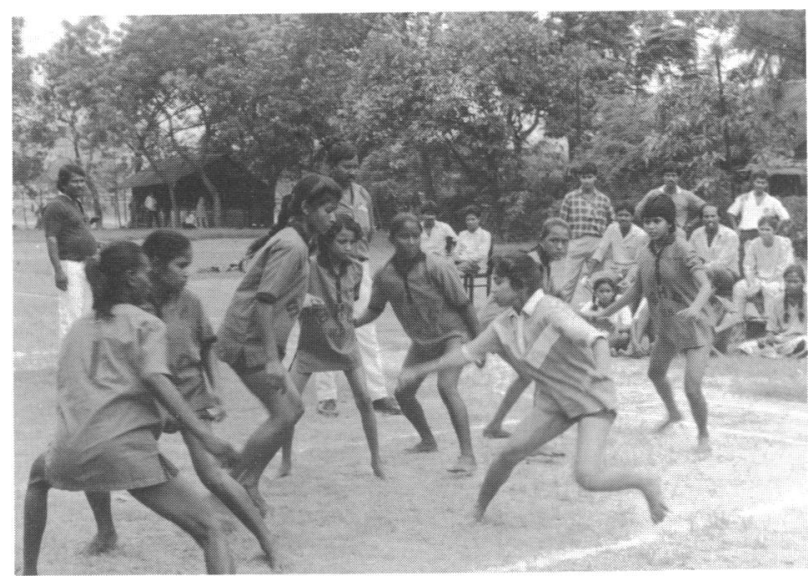

Figure 4. Kabaddi game in progress

strength was found to be lower than that of judokas ${ }^{14}$ (187.4(22.4)). The higher strength observed in kabaddi players may be due to their body weight because the mean body weight of kabaddi players was higher than that for the other events. The other factor that may contribute to higher strength is the specific training given to the teams to achieve best performances.

Maximum oxygen uptake capacity $\left(\dot{V}_{\mathrm{O}_{2} \max }\right)$ which indicates a person's capability to consume oxygen at maximum effort at sea level is a good criterion for studying the endurance capacity of sports persons ${ }^{15,16}$. Movements of the body on a continuous basis, sometimes relatively slowly and sometimes quite quickly, brings in to play all the components of endurance. The maximal oxygen uptake capacity is the best overall measure of aerobic power. With regard to maximum oxygen uptake capacity the present data are well behind those for other events. But wrestlers and volleyballers are almost similar to the present value. Reilly and Seaton ${ }^{13}$ also reported higher $\dot{V}_{\mathrm{O}_{2} \max }$ values for élite boxers and wrestlers $\left(65 \mathrm{ml} \mathrm{kg}^{-1} \mathrm{~min}^{-1}\right.$ and $57 \mathrm{ml} \mathrm{kg}^{-1} \mathrm{~min}^{-1}$, respectively). The mean $\dot{V}_{\mathrm{O}_{2} \text { max }}$ of 20 college rugby forwards was reported to be $46.3 \mathrm{ml} \mathrm{kg}^{-1} \mathrm{~min}^{-1}$ in a university rugby union team ${ }^{17}$ which is not significantly higher than the present study. Taylor and Brasard ${ }^{18}$ studying Canadian judokas and Matsumoto et al. ${ }^{19}$, studying Japanese judo players have also reported higher $\dot{V}_{\mathrm{O}_{2} \max }$ values in comparison to present data.

The other physiological parameters that reflect cardiorespiratory fitness, such as maximum pulmonary ventilation of the kabaddi players, were found to be higher than those of other events such as judo, boxers, weightlifters etc., but lower than road cyclists. It may be due to the breathing exercises done by the participants who are accustomed to taking a maximum inspiration followed by slow expiration along with the chant during the course of the game. Pulmonary function values are also higher in inter-university kabaddi players than the Indian sedentary population ${ }^{20}$, possibly confirming the above view.

The other important cardiorespiratory fitness index measured was oxygen pulse $\left(\mathrm{O}_{2}\right.$ pulse). This reflects the amount of oxygen delivered to the muscles per unit heart beat. It is dependent on the cardiac output and thus on the oxygen binding capacity of the blood as well as on the peripheral oxygen utilization. Hence, it gives a good insight into the cardiorespiratory fitness of an individual ${ }^{16}$. In the present investigation, the mean(s.d.) $\mathrm{O}_{2}$ pulse $(17.4(2.17) \mathrm{ml}$ per beat) was found to be higher than that of Indian sedentary people $(12.9(1.89) \mathrm{ml}$ per beat) reported by Khanna et al. ${ }^{14}$ and comparable to that of judoists and boxers (20.1(1.9) and 17.4(1.7) $\mathrm{ml}$ per beat) respectively. Similarly, the maximum(s.d.) heart rate was lower than that of sedentary people $(193(7.74)$ beats per min) reported by Chatterjee et al. ${ }^{21}$. A decrease in maximum heart rate together with an increase in oxygen consumption indicates that the stroke volume seems to be higher in the case of sports persons. This also signifies that they can tolerate a higher workload with less cardiac stress.

From the present study it may be concluded that a mesomorphic endomorph physique will suit sports like kabaddi. The back strength of the present kabaddi players was found to be good according to a survey of Indian sportsmen. Although the aerobic $\left(\dot{V}_{\mathrm{O}_{2} \max }\right)$ and anaerobic (oxygen debt) capacity measured in the present study was higher than that of normal sedentary persons, it was not satisfactory compared with other games. Kabaddi is an intermittent type of sport and its demands can be met by an optimum level of aerobic and anaerobic capacity. Other cardiorespiratory fitness indices were observed to be better in the kabaddi players than in sedentary persons. The standard values (physical and physiological) will serve as a reference standard for comparison. It may also be recommended that physical characteristics, body composition and physiological variables be monitored throughout individual training programmes. Such assessments will be beneficial to these athletes in preparation for their respective competitive events.

\section{Acknowledgements}

The authors are indebted to Mr C. V. Chandrashekar, Laboratory Technician, for his help in preparing the manuscript.

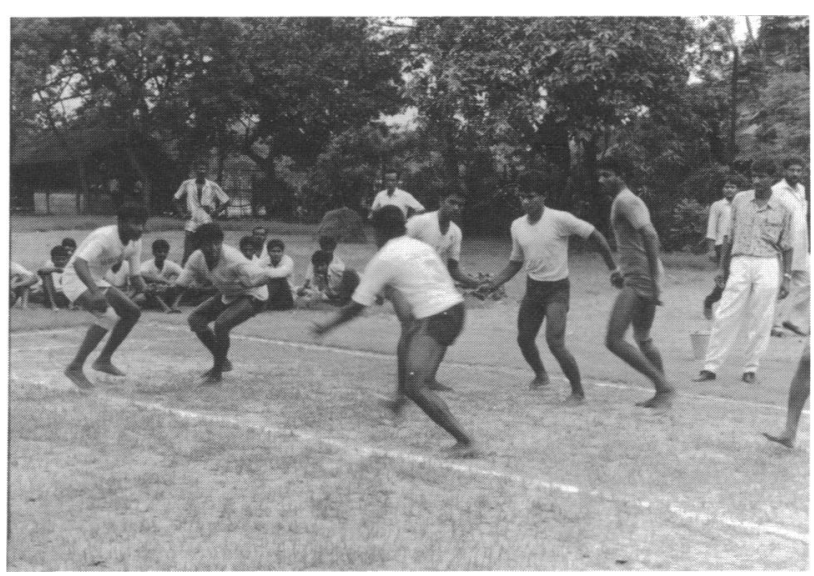

Figure 5. Kabaddi game in progress 


\section{References}

1 De AK, Debnath PK, Nagchaudhuri J. A comparison of physical efficiency between female volleyball and kabaddi players. Soc Natl Inst Phys Ed Sports J 1979; 2: 46-50.

2 Heath BH, Carter JEL. A modified somatotype method. Am I Phys Anthrop 1967; 27: 57-74.

3 Siri WE. In: Brozak JA, ed. Technique for Measuring Body Composition. Washington, USA: National Academy of Science National Research Council, 1961: 223-44.

4 Durnin JVGA, Rahaman MM. The assessment of the amount of fat in the human body from measurement of skinfold thickness. Br J Nutr 1967; 21: 681-9.

5 Fox EL, Robinson S, Weigman D. Metabolic energy sources during continuous and interval running. J Appl Physiol 1969; 27: 174-8.

6 Sodhi HS, Sidhu LS. Physique and Selection of Sportsmen. A Kinenthropometric Study. Patiala, India: Punjab Publishing House, 1984

7 Morehouse LE, Rasch PJ. Sports Medicine for Trainers. 2nd edn. Philadelphia, USA: WB Saunders, 1964.

8 Tappen NC. An anthropometric and constitutional study of championship weight lifters. Am J Phys Anthrop 1950; 8: 64-9.

9 Tanner JM. The Physique of the Olympic Athlete. London, UK: Allen and Unwin, 1964.

10 DeGaray AL, Levine L, Carter JEL. Genetic and Anthropological Studies of Olympic Athletes. New York, USA: Academic Press, 1974.

11 Reilly T, Hardiker R. Somatotype and injuries in adult student rugby football. J Sports Med Phys Fit 1981; 21: 186-91.

12 Boennec PM, Prevot M, Ginet J. Somatotype de sportif de haut niveau, resultats dans huit disciplines differentes. Med Sport 1980; 54: 45-54.

13 Reilly T, Seaton A. Physiological strain unique to field hockey. I Sports Med Phys Fit 1990.

14 Khanna GL, Ghosh AK, Sharma JG, Malhotra MS. Physiological status of some judoists in India. SNIPES J 1983; 6: 21-7.

15 Saltin B, Astrand PO. Maximal oxygen uptake in athletes. J Appl Physiol 1967; 23: 353-8.

16 Astrand PO, Rodahl K. Textbook of Work Physiology. Tokyo, Japan: McGraw Hill, 1970.

17 Williams G, Reid RM, Coutts R. Observations on the aerobic power of university rugby players and professional soccer players. Br J Sports Med 1973; 7: 390-1.

18 Taylor WA, Brasard L. Physiological profile of Canadian judo team. I Sports Med Phys Fit 1981; 21: 160-4.

19 Matsumoto Y, Seinkichi D, Yoshimichi F, Takashi O. Studies in the training of the judoist investigation in the training in general endurance. Bull Assoc for Scientific Studies in Judo. Kodokan, Report V, 1972; 7-17.

20 De AK, Debnath PK, Panda BK, Bhatacharya AK. Physical efficiency and tests on Indian male kabaddi inter-university players. Br J Sports Med 1982; 16: 33-6.

21 Chatterjee S, Dey SK, Nag SK. Maximum oxygen uptake capacity of smokers of different age groups. Jpn J Physiol 1987; 37: 837-50.

\title{
SPORTS MEDICINE
} BOOKS!

\author{
STANDARD TEXTS AND \\ NEWLY PUBLISHED TITLES
}

SEND FOR YOUR FREE BOOKLIST TO:

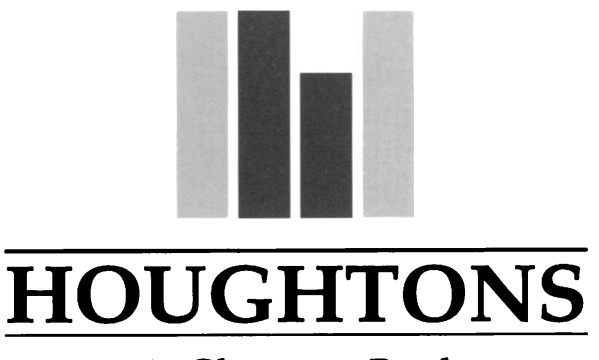

17 Gloucester Road

Alkrington

Middleton

Manchester M24 1HT

Tel/Fax: 0616547831 